\title{
Fear Of Missing Out ditinjau dari Big Five Personality
}

\author{
Nurul Hidayati ${ }^{1}$, Auliya Syaf ${ }^{2}$, Rini Hartati ${ }^{3}$ \\ ${ }^{1,2,3}$ Fakultas Psikologi dan Ilmu Sosial, Program studi Psikologi-Universitas Abdurrab \\ Kampus 3, Jalan Pattimura No 1.Cinta Raja-Sail.
}

auliya.syaf@univrab.ac.id

\begin{abstract}
Abstrak
Media sosial membantu individu mendapatkan informasi yang diinginkan dan ini memberikan efek ketagihan. Efek ketagihan ini akan membuat penggunanya mengalami fear of missing out ditandai oleh individu dengan keingintahuan terhadap aktivitas dan atau terhubung dengan orang lain. Setiap individu dengan kepribadian memberikan dampak berbeda pula pada munculnya FoMO. Penelitian ini menggagas asumsi hubungan big five personality dengan FoMO. Partisipan penelitian berjumlah 204 orang diambil menggunakan quota sampling. Penelitian menggunakan skala big five inventory dan skala FoMO. Temuan penelitian mengungkap bahwa kepribadian agreeableness memiliki korelasi dengan FoMO ( $\operatorname{sig}=0,015 ; \mathrm{p}<0,05)$. Namun, tidak ada korelasi antara extraversion, neuroticism, conscientiousness maupun openness, terhadap FoMO pada masyarakat Pekanbaru.
\end{abstract}

Kata kunci: big five personality; fear of missing out; social media

\begin{abstract}
Social media helps individuals get the information they want and this has an addictive effect. This addictive effect will make users experience a fear of missing out, which is indicated by individuals who have curiosity about activities and / or connect with other people. Each individual with a personality has a different impact on the emergence of FoMO. This study proposes the assumption of the big five personality relationship with FoMO. The number of participants in the study was 204 people taken using quota sampling. This research uses the big five inventory scale and the fear of missing out scale. The findings of this study reveal that agreeableness personality has a correlation with FoMO $(\mathrm{sig}=0.015 ; \mathrm{p}<0.05)$. However, there is no correlation between extraversion, neuroticism, conscientiousness or openness towards FoMO in the people of Pekanbaru.
\end{abstract}

Keywords: big five personality; fear of missing out; social media

\section{PENDAHULUAN}

Beberapat tahun terakhir internet terus berkembang dengan kecepatan tinggi dan selalu ada peningkatan dalam pengguna internet (Kurbalija, 2011). Di Indonesia pengguna internet terus mengalami peningkatan. Sumatera sebagai salah satu wilayah di Indonesia yang menggunakan internet terbanyak setelah Pulau Jawa. Hasil survei menunjukkan bahwa dalam sehari sekitar 19,6\% individu menggunakan internet selama 7 hingga 8 jam (Asosiasi Penyelenggara Jasa Internet Indonesia, 2018).

Individu dapat menggunakan perangkat mobile atau yang dikenal dengan smartphone untuk terhubung dengan internet (Daeng et al., 2017). Asosiasi Penyelenggara Jasa Internet Indonesia (2018) menemukan bahwa media sosial merupakan urutan kedua alasan paling utama penggunaan internet setelah komunikasi lewat pesan.

Adanya berbagai jenis media sosial, membuat individu dapat berbagi konten yang bermacam-macam, seperti: membagikan aktifitas sehari-hari, kegiatan hari-hari besar, dan sebagai sarana hiburan (Triastuti et al., 2017). Banyaknya hal yang dapat dilakukan dengan media sosial, ini dapat memberikan berbagai dampak bagi penggunanya, diantaranya untuk 
seorang pengusaha dapat menggunakan media sosial sebagai media marketing untuk mempromosikan bisnis atau usaha (Ayutiani \& Putri, 2018).

Berbagai dampak yang dirasakan oleh penggunanya akan membuat media sosial menjadi sebuah kebutuhan (Solekhan \& Winarso, 2014). Kebutuhan untuk membagikan peristiwa yang terjadi, mendapatkan informasi, dan berbagi informasi kepada orang lain (Błachnio \& Przepiórka, 2018). Mudahnya dalam mengakses media sosial membuat individu mendapatkan informasi yang diinginkan dan ini memberikan efek ketagihan (Abel et al., 2016). (Blackwell et al., 2017)me ngungkapkan dampak negatif dalam menggunakan sosial media yang berlebihan selain kecanduan juga menyebabkan munculnya FoMo atau Fear of Missing Out. Media sosial erat kaitannya dengan FoMo (JWT, 2011) sebab media sosial mempunyai peran penting membuat individu menjadi FoMO (Abel et al, 2016).

Individu dengan FoMO cenderung akan mencari hal-hal yang dilakukan orang lain dan selalu ingin terhubung dengan orang lain (Przybylski et al., 2013) maupun dengan dan atau media sosial (Listari, 2018). FoMo juga akan menggunakan smartphone secara berlebihan agar tetap terhubung ke media sosialnya (Alt, 2015; Elhai et al., 2016). Individu yang memiliki FoMO yang tinggi akan selalu mencari informasi melalui media sosial dimana saja, bahkan saat berkendara mereka tetap menggunakan smartphone-nya untuk mencari informasi (Przybylski et al., 2013). Ini sejalan dengan yang dikatakan Abel et al. (2016); Lim, Phau, Cheah, dan Teah (2015); Marlina (2017) bahwa individu dengan FoMO yang tinggi akan sering memeriksa media sosialnya. Individu tersebut tanpa sadar telah menghabiskan banyak waktu dan energi (JWT, 2012).

Banyak faktor yang dapat menjadi penyebab timbulnya FoMO, salah satunya adalah kepribadian. Tresnawati (2016) menjelaskan bahwa kepribadian berhubungan dengan FoMO. Kepribadian merupakan suatu karakteristik dinamik dan terorganisasi yang dimiliki individu sehingga memengaruhi kognisi, motivasi, serta perilaku (Ramdhani, 2007). Kepribadian relatif permanen dan memiliki khas atau keunikan pada setiap individu (Alwisol, 2016; Feist \& Feist, 2008). Kepribadian dikatakan unik karena bentukan dari faktor internal, seperti pembawaan yang sudah menetap pada diri individu (Larasati \& Fitria, 2016). Kepribadian yang relatif menetap membuat individu bersikap sesuai dengan kapasitas tuntutan maupun tujuan yang sudah ditetapkan (Rosito, 2018). Hal ini membuat kepribadian menjadi aspek psikologis yang penting bagi individu dalam berperilaku (Mastuti, 2005). Kepribadian big five merupakan pengelompokkan dari ribuan kata sifat menjadi lima himpunan besar yang dikenal dengan big five personality (Ramdhani, 2012). John, Naumann, dan Soto (2008) mengatakan bahwa big five personality adalah ; extraversion, openness, neuroticism, dan conscientiousness serta agreeableness. Kepribadian menjadi satu dari beberapa faktor bagi individu dalam mengalami FoMO, di tambah lagi dengan keberadaan media sosial saat ini. Hasil penelitian dari Triani \& Ramdhani (2017) mengungkapkan bahwa kebutuhan berelasi menjadi penyebab munculnya FoMO pada individu Angesti dan Oriza (2018), serta ditambah dengan kemudahan penggunaan media sosial bagi individu untuk berkomunikasi dengan pihak lain. Berdasarkan hal ini peneliti tertarik mencari tahu hubungan kepribadian big five dan FoMO.

\section{METODE}

Subjek dalam penelitian ini berjumlah 204 dengan kisaran usia 14-66 tahun, memiliki media sosial dan smartphone. Subjek diambil dengan prosedur Quota Sampling, sedang data dikumpulkan dengan menyebarkan skala BFI versi bahasa dari Ramdhani (2012) berasal dari teori John dan Srivastava (1999). Skala FoMo disusun berdasarkan indikator-indikator dari Przybylski, Murayama, Dehaan, dan Gladwell (2013) yaitu: ketakutan (fears), kekhawatiran 
(worries), dan kecemasan (anxieties). Masing-masing skala menggunakan model respon rating scale, yang diskoring 1 sampai 5.

\section{HASIL}

Tabel 1.

Deskripsi Statistik FoMO

\begin{tabular}{ccccccccc}
\hline & \multicolumn{4}{c}{ Empirik } & \multicolumn{4}{c}{ Hipotetik } \\
\cline { 2 - 10 } & Mak & Min & $\widetilde{\boldsymbol{X}}$ & $\boldsymbol{\sigma}$ & Mak & Min & $\widetilde{\boldsymbol{X}}$ & $\boldsymbol{\sigma}$ \\
\hline FoMO & 73 & 21 & 40,3 & 11,7 & 90 & 18 & 54 & 12 \\
\hline
\end{tabular}

Melalui tabel 1 dapat di ketahui bahwa mean (rata-rata) FoMO empirik adalah 40,3, lebih kecil daripada mean (rata-rata) hipotetik yaitu 54. Hal ini menunjukkan bahwa FoMO partisipan penelitian memiliki FoMO yang rendah.

Tabel 2.

Kategorisasi Variabel Fear of Missing Out (Y)

\begin{tabular}{cccc}
\hline Kategori & Nilai & Frekuensi & Persentasi (\%) \\
\hline Sangat Rendah & $\mathrm{X} \leq 36$ & 76 & $37,3 \%$ \\
Rendah & $36<\mathrm{X} \leq 48$ & 73 & $35,8 \%$ \\
Sedang & $48<\mathrm{X} \leq 60$ & 45 & $22,1 \%$ \\
Tinggi & $60<\mathrm{X} \leq 72$ & 7 & $3,4 \%$ \\
Sangat Tinggi & $72 \leq \mathrm{X}$ & 3 & $1,4 \%$ \\
Jumlah & & $\mathbf{2 0 4}$ & $\mathbf{1 0 0 \%}$ \\
\hline
\end{tabular}

Berdasarkan tabel 2. dapat dilihat bahwa frekuensi FoMO yang tertinggi ada pada kategori sangat rendah yaitu $37,3 \%$, sedangkan yang paling sedikit frekuensinya adalah FoMO dengan kategori sangat tinggi yaitu $1,4 \%$. Dengan kata lain bisa di ungkapkan bahwa FoMO dalam partisipan dalam penelitian ini memiliki FoMO yang sangat rendah.

Tabel 3.

Hasil Uji Hipotesa

\begin{tabular}{ccccc}
\hline Variabel & Sig. & Beta & t & Ket \\
\hline $\begin{array}{c}\text { Extraversion dengan FoMO } \\
\text { Agreeableness dengan FoMO }\end{array}$ & 0,307 & $-0,067$ & $-0,720$ & Tidak \\
$\begin{array}{c}\text { Sonscientiousness dengan } \\
\text { FoMO }\end{array}$ & 0,015 & 0,169 & 1,913 & Signifikan \\
Tidak \\
$\begin{array}{c}\text { Neuroticism dengan FoMO } \\
\text { Tifikan } \\
\text { Tidak } \\
\text { Openness dengan FoMO }\end{array}$ & 0,073 & 0,097 & 1,039 & $\begin{array}{c}\text { Signifikan } \\
\text { Tidak }\end{array}$ \\
& 0,359 & $-0,159$ & $-1,788$ & Signifikan \\
\hline
\end{tabular}

Ket : $\mathrm{P}<0,05$

Melalui analisis regresi berganda hasil analisis masing-masing variabel bisa dilihata pada tabel 3. Nilai Sig. pada tabel 3 menunjukkan arah korelasi dari masing-masing variabel big five personality dengan FoMO. Dimana diantara kelima variabel big five personality hanya ada satu komponen yang hipotesanya di terima dengan hasil Sig. sebesar 0,015 pada agreeableness yaitu "Ada hubungan antara kepribadian agreeableness dengan FoMO" 


\section{DISKUSI}

Melalui penelitian ini diketahui kepribadian agreeableness berkaitan dengan FoMO. Temuan ini sejalan dengan hasil penelitian Tresnawati (2016) bahwasanya kepribadian agreeableness memiliki hubungan dengan FoMO. Individu dengan kepribadian agreeableness memiliki kepercayaan, simpati, empati, kesederhanaan, dan suka terang-terangan (Pervin et al., 2010). Tresnawati (2016) juga menambahkan bahwa semakin tinggi agreeableness, maka semakin tinggi pula FoMO yang dirasakan individu tersebut. Individu dengan Kepribadian ini biasanya menyukai kegiatan sosial sehingga individu lain bisa terinspirasi (Marshall et al., 2015). Dengan demikian hal ini dapat berdampbak pada ketakutan individu akan ketinggalan berita, jika memiliki tingkat agreeableness yang tinggi(Tresnawati, 2016).

Kepribadian conscientiousness tidak memiliki hubungan dengan FoMO pada masyarakat Pekanbaru. Hasil penelitian ini didukung penelitian Tresnawati (2016) bahwasanya kepribadian conscientiousness tidak berkorelasi dengan FoMO. Selain itu, terdapat inkonsistensi hasil penelitian Stead dan Bibby (2017) bahwasanya kepribadian conscientiousness berkorelasi negatif dengan FoMO. Tidak hanya itu, hasil penelitian yang dilakukan Amichai-Hambuger et al (dalam Stead \& Bibby, 2017) bahwa ditemukan kepribadian conscientiousness berkorelasi negatif dengan FoMO. Temuan ini dapat dijelaskan oleh karakteristik dari kepribadian conscientiousness yang mana individu akan berpikir sebelum bertindak, mengatur, dan memperioritaskan tugas (John, Robins, \& Pervin, 2008).

Kepribadian neuroticism maupun extraversion juga tidak memiliki hubungan dengan FoMO. Pada neuroticism, ilndividu dengan kepribadian ini biasanya cemas, gugup, emosional, dan mudah terganggu (Pervin et al., 2010). Swickert (dalam Tresnawati, 2016) mengatakan bahwa orang dengan kepribadian ini sering kali memiliki Batasan dalam menetapkan suatu hal termasuk dalam informasi online, hal ini berakar dari ketidakpercayaan yang melekat pada kepribadian ini. Sedang menurut Pervin et al. (2010) individu dengan kepribadian extraversion tinggi biasanya dapat bersosialisasi, aktif, senang bercakap-cakap, maupun berorientasi pada interaksi dengan orang lain. Sebagai tambahan, individu dengan kepribadian ini extraversion cenderung untuk bersosialisasi dan mengalami pengaruh positif (Besser \& Shackelford, 2007), memiliki kemudahan dalam berinteraksi dengan orang lain, ataupun hubungan interpersonal serta senang bertemu dengan orang lain (Ramdhani, 2007). Karena itulah individu dengan extraversion lebih memilih untuk berkomunikasi secara langsung dengan orang lain.

Sama halnya dengan kepribadian openness tidak menunjukkan ada hubungan dengan FoMO pada masyarakat Pekanbaru, Individu dengan kepribadian openness cenderung intelektualisme, idealisme, dan berpetualang (John, Robins, \& Pervin, 2008), memiliki keingintahuan yang tinggi dan senang berdiskusi (McCrae \& Costa, 2006). Sehingga individu yang memiliki kepribadian openness cukup berinteraksi secara langsung dalam kehidupan sehari-hari (Prasetyo \& Ariana, 2016). Selain itu, individu dengan kepribadian openness cenderung menjadi tempat individu lain untuk meminta pendapat (Lee et al., 2014). Sehingga tidak mengherankan individu dengan kepribadian openness tidak memerlukan smartphone untuk sering berinteraksi dengan orang lain (Prasetyo \& Ariana, 2016).

\section{KESIMPULAN}

Penelitian ini menggambarkan bahwa individu yang memiliki kecendrungan FoMo adalah individu dengan kepribadian agreeableness. Meskipun dicirikan dengan tampilkan sederhana, dilain hal individu dengan kepribadian ini cenderung terang-terangan dan menyukai menjadi inspirasi bagi orang lain, sehingga hal ini dapat menyebabkan individu dengan kepribadian ini 
tidak mau ketinggalan berita, termasuk FoMO. Sementar ke empat kepribadian big five lainnya tidak memiliki hubungan dengan FoMO, ini dapat terjadi karena karakteristik dari kepribadian itu sendiri. Temuan ini menegaskan kembali temuan sebelumnya, namun tentu tetap bisa kembali di eksplorasi pada penelitian berikutnya, mengingat kompleksitas dari kepribadian big five ini.

\section{DAFTAR PUSTAKA}

Abel, J. P., Buff, C. L., \& Burr, S. A. (2016). Social Media and the Fear of Missing Out: Scale Development and Assessment. Journal of Business \& Economics Research (JBER), 14(1), 33-44. 10.19030/jber.v14i1.9554

Alt, D. (2015). College students' academic motivation, media engagement and fear of missing out. Computers in Human Behavior, 49, 111-119. 10.1016/j.chb.2015.02.057

Alwisol. (2016). Psikologi Kepribadian. UMM Press.

Angesti, R., \& Oriza, I. D. I. (2018). Peran Fear of Missing Out (Fomo) Sebagai Mediator Antara Kepribadian Dan Penggunaan Internet Bermasalah. Jurnal Muara Ilmu Sosial, Humaniora, Dan Seni, 2(2), 790. 10.24912/jmishumsen.v2i2.2317

Asosiasi Penyelenggara Jasa Internet Indonesia. (2018). Penetrasi dan Perilaku Pengguna Internet Indonesia. Apjii, Penetrasi dan Perilaku Pengguna Internet Indonesia, 1-34.

Ayutiani, D. N., \& Putri, B. P. S. (2018). Penggunaan Akun Instagram sebagai Media Informasi Wisata Kuliner. 3(1), 39-59.

Besser, A., \& Shackelford, T. K. (2007). Mediation of the effects of the big five personality dimensions on negative mood and confirmed affective expectations by perceived situational stress: A quasi-field study of vacationers. Personality and Individual Difference, 42, 1333-1346. 10.1016/j.paid.2006.10.011

Beyens, I., Frison, E., \& Eggermont, S. (2016). "I don't want to miss a thing": Adolescents' fear of missing out and its relationship to adolescents' social needs, Facebook use, and Facebook related stress. Computers in Human Behavior, 64, 1-8. 10.1016/j.chb.2016.05.083

Błachnio, A., \& Przepiórka, A. (2018). Facebook intrusion, fear of missing out, narcissism, and life satisfaction: A cross-sectional study. Psychiatry Research, 259, 514-519. 10.1016/j.psychres.2017.11.012

Blackwell, D., Leaman, C., Tramposch, R., Osborne, C., \& Liss, M. (2017). Extraversion, neuroticism, attachment style and fear of missing out as predictors of social media use and addiction. Personality and Individual Differences, 116, 69-72. 10.1016/j.paid.2017.04.039

Daeng, I. T. M., Edmon, N. . M., \& Kalesaran, E. R. (2017). Penggunaan Smartphone Dalam Menunjang Aktivitas Perkuliahan Oleh Mahasiswa Fispol Unsrat Manado. E-Journal Acta Diurna, VI(2), 1-15.

Elhai, J. D., Levine, J. C., Dvorak, R. D., \& Hall, B. J. (2016). Fear of missing out, need for touch, anxiety and depression are related to problematic smartphone use. Computers in Human Behavior, 63, 509-516. 10.1016/j.chb.2016.05.079

Feist, J., \& Feist, G. J. (2008). Theories Of Personality, Seventh Edition. In McGraw-Hill Primis. 10.1017/CBO9781107415324.004

John, O. P., Naumann, L. P., \& Soto, C. J. (2008). Chapter 4 Paradigma Shift To The Integrative Big Five Trait Taxonomy.

John, O. P., Robins, R. W., \& Pervin, L. A. (2008). Handbook of Personality Theory and Research. In The Guilford Press (Third). The Guilford Press. 10.2307/3005768

John, O. P., \& Srivastava, S. (1999). The Big-Five Trait Taxonomy: History, Measurement, and Theoretical Persepectuve. 1-71. 10.1109/ICARM.2016.7606898 
JWT. (2011). Fear Of Missing Out (FOMO). JWTIntelligence, May.

JWT. (2012). Fear Of Missing Out (FOMO). J. Walter Thompson Company, March.

Kurbalija, J. (2011). Sebuah Pengantar Tentang Tata Kelola Internet (Edisi Ke I). APJIIwww.apijii.or.id.

Larasati, A., \& Fitria, M. (2016). Kecenderungan Perilaku Cyberbullying Ditinjau dari Trait dalam Pendekatan Big-Five Personality pada Siswa Sekolah Menengah Atas Negeri di Kota Yogyakarta. Jurnal Psikologi Positif, 4, 161-182.

Lee, S., Tam, C. L., \& Chie, Q. T. (2014). Mobile Phone Usage Preferences: The Contributing Factors of Personality, Social Anxiety and Loneliness. Social Indicators Research, 118(3), 1205-1228. 10.1007/s11205-013-0460-2

Lim, W., Phau, I., Cheah, I., \& Teah, M. (2015). The Fear Of Missing Out. Global Fashion Management Conference at Florence, June, 152-158.

Listari, R. (2018). Peran fear of missing out (FoMO) dan kontrol diri terhadap kecenderungan adiksi media sosial pada remaja. In Electronic Theses \& Dissertations (ETD). Universitas Gadjah Mada.

Marlina, R. D. (2017). Hubungan Antara Fear Of Missing Out (Fomo) Dengan Kecenderungan Kecanduan Internet Pada Emerging Adulthood. Naskah Publikasi, 1-12.

Marshall, T. C., Lefringhausen, K., \& Ferenczi, N. (2015). The Big Five, self-esteem, and narcissism as predictors of the topics people write about in Facebook status updates. Personality and Individual Differences, 85, 35-40. 10.1016/j.paid.2015.04.039

Mastuti, E. (2005). Analisis Faktor Alat Ukur Kepribadian Big Five (Adaptasi dari IPIP) pada Mahasiswa Suku Jawa. INSAN, 7(3), 264-276.

McCrae, R. R., \& Costa, P. T. (2006). Personality in adulthood A Five-Factor Theory Perspective. In Experimental Aging Research (Paperback, Vol. 12, Issue 1). The Guilford Press. 10.1080/03610738608259434

Pervin, L. A., Cervone, D., \& John, O. P. (2010). Psikologi Kepribadian Teori dan Riset (Edisi Kese). Kencana.

Prasetyo, A., \& Ariana, A. D. (2016). Hubungan antara The Big Five Personality dengan Nomophobia pada Wanita Dewasa Awal. Jurnal Psikologi Klinis Dan Kesehatan Mental, $5(01), 1-9$.

Przybylski, A. K., Murayama, K., Dehaan, C. R., \& Gladwell, V. (2013). Motivational, emotional, and behavioral correlates of fear of missing out. Computers in Human Behavior, 29(4), 1841-1848. 10.1016/j.chb.2013.02.014

Ramdhani, N. (2007). Apakah Kepribadian Menentukan Pemilihan Media Komunikasi? Metaanalisis Terhadap Hubungan Kepribadian Extraversion, Neuroticism, dan Openness to Experience dengan Penggunaan Email. Jurnal Psikologi, 34(2), 112-129.

Ramdhani, N. (2012). Adaptasi Bahasa dan Budaya Inventory Big Five. Jurnal Psikologi, 39(2), 189-207. 10.1016/S0143-4004(97)90091-6

Rosito, A. C. (2018). Eksplorasi Tipe Kepribadian Big Five Personality Traits Dan Pengaruhnya Terhadap Prestasi Akademik. Jurnal Psikologi Pendidikan Dan Konseling, 4(1), 6. https://doi.org/10.26858/jpkk.v4i1.3250

Solekhan, \& Winarso, R. (2014). Pemanfaatan Media Sosial Sebagai Media Pemasaran Sangkar Burung di Kabupaten Kudus. Prosiding SNATIF, 445-448. 10.2298/PAN0903301G

Stead, H., \& Bibby, P. A. (2017). Personality, fear of missing out and problematic internet use and their relationship to subjective well-being. Computers in Human Behavior, 76, 534540. 10.1016/j.chb.2017.08.016

Tresnawati, F. R. (2016). Hubungan Antara the Big Five Personality Traits Dengan Fear of 
Missing Out About Social Media Pada Mahasiswa. Intuisi : Jurnal Psikologi Ilmiah, 8(3), 179-185.

Triani, C. I., \& Ramdhani, N. (2017). Hubungan Kebutuhan Berelasi dan Fear of Missing Out dengan Harga Diri sebagai Variabel Moderator. Universitas Gadjah Mada.

Triastuti, E., Adrianto, D., \& Nurul, A. (2017). Kajian Dampak Penggunaan Media Sosial Bagi Anak Dan Remaja. Pusat Kajian Komunikasi, FISIP Universitas Indonesia. 